\title{
How Necessary is the Vasculature in the Life of Neural Stem and Progenitor Cells? Evidence from Evolution, Development and the Adult Nervous System
}

\author{
Christos Koutsakis ${ }^{1}$ and llias Kazanis ${ }^{1,2 *}$ \\ ${ }^{1}$ Laboratory of Developmental Biology, Department of Biology, University of Patras, Patras, Greece, ${ }^{2}$ Wellcome Trust-MRC \\ Cambridge Stem Cell Institute, University of Cambridge, Cambridge, UK
}

OPEN ACCESS

Edited by:

Francesco Moccia,

University of Pavia, Italy

Reviewed by:

Joanne C. Conover, University of Connecticut, USA

Gourav Roy Choudhury, Texas Biomedical Research Institute,

USA

*Correspondence: Ilias Kazanis ik255@cam.ac.uk

Received: 14 October 2015 Accepted: 01 February 2016 Published: 16 February 2016

Citation:

Koutsakis C and Kazanis I (2016) How Necessary is the Vasculature in the Life of Neural Stem and

Progenitor Cells? Evidence from Evolution, Development and the Adult Nervous System.

Front. Cell. Neurosci. 10:35. doi: 10.3389/fncel.2016.00035
Augmenting evidence suggests that such is the functional dependance of neural stem cells (NSCs) on the vasculature that they normally reside in "perivascular niches". Two examples are the "neurovascular" and the "oligovascular" niches of the adult brain, which comprise specialized microenvironments where NSCs or oligodendrocyte progenitor cells survive and remain mitotically active in close proximity to blood vessels (BVs). The often observed co-ordination of angiogenesis and neurogenesis led to these processes being described as "coupled". Here, we adopt an evo-devo approach to argue that some stages in the life of a NSC, such as specification and commitment, are independent of the vasculature, while stages such as proliferation and migration are largely dependent on BVs. We also explore available evidence on the possible involvement of the vasculature in other phenomena such as the diversification of NSCs during evolution and we provide original data on the senescence of NSCs in the subependymal zone stem cell niche. Finally, we will comment on the other side of the story; that is, on how much the vasculature is dependent on NSCs and their progeny.

Keywords: neural stem cells, vasculature, blood vessels, neurogenesis, proliferation, differentiation, migration, stem cell niche

\section{INTRODUCTION}

The observation that neurogenesis and angiogenesis are seasonally coordinated in the brain of songbirds (Louissaint et al., 2002) produced the first evidence on the existence of a cross-talk between neural stem cells (NSCs) and blood vessels (BVs). More recently, it was shown that endothelial cells control the function of adult brain NSCs via direct cell contact and diffusible signals (Ottone and Parrinello, 2015). But is this the truth and nothing but the truth? The first neurons and glia appeared in animals that had no vasculature (Satterlie, 2015) and in early neurodevelopmental stages of mammals NSCs emerge and form the neural tube in the absence of vascularization. This strongly suggests that NSCs can exist and function in the absence of BVs and raises the challenging question: how much does the existence and the function of NSCs depend on the vasculature?

To address this question in a systematic and comprehensive way we defined the major functional stages in the life of a NSC, informed both by evolution and development 


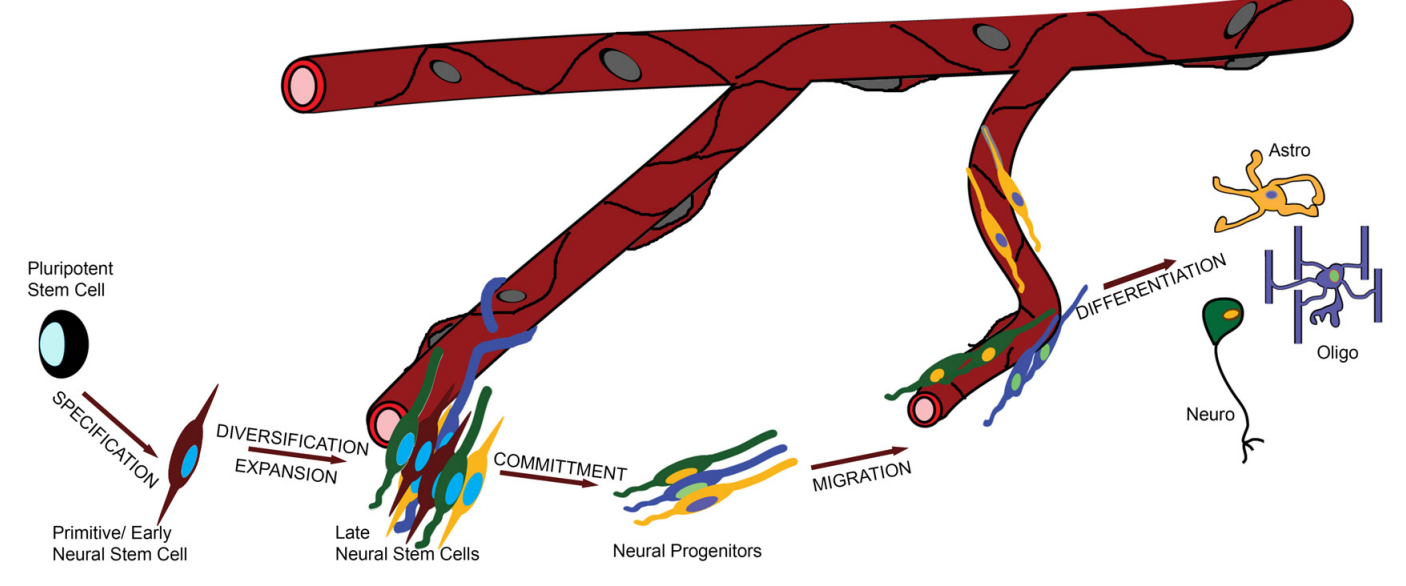

FIGURE 1 | The role of the vasculature in the life of a neural stem cell (NSC). In this graphic illustration, the different stages in the life of a NSC are shown and the involvement of the vasculature is depicted by the distance of the cells from the blood vessels (BVs). For example, specification and commitment of NSCs appear to happen away from the vessels, whilst proliferation and migration in close proximity.

(Figure 1): (i) specification of NSC identity from earlier pluripotent-e.g., embryonic or ancestral stem cells; (ii) proliferation/diversification, during which the pool of NSCs is expanded and becomes heterogeneous; (iii) commitment to a specific fate (such as neuronal or glial); (iv) migration and finally; (v) differentiation. During stage (iii) NSCs become, or give rise to, neural progenitors, and overall migration can be minimal or absent.

\section{GENERALIZATIONS}

\section{The In Vitro Life of NSCs}

Neural stem cell culture protocols (iPSCs, primary cells, cell lines) have proven that all stages in the life of a NSC can be recapitulated in vitro. Embryonic or induced stem cells can be programmed to adopt NSC fate and can be differentiated into a range of neuronal and glial cell types. This, obviously, does not exclude the possibility that BVs or their ancestral systems are necessary in vivo, especially as cell culture media are rich in components that are provided by BVs in the tissue. Endothelial cells have been found to enhance neurogenesis in many cell culture assays, but few studies have gone the extra mile to directly link these in vitro results to the role of endothelial cells in the live organism (Shen et al., 2004; Androutsellis-Theotokis et al., 2010).

\section{Main Mechanisms of NSC-BV Interaction}

NSC-BV interaction can be achieved through three different, but possibly co-operating, mechanisms. First, via direct contact between NSCs and BV components, such as endothelial cells and perivascular extracellular matrix (Javaherian and Kriegstein, 2009; Ottone et al., 2014). Second, via diffusible signals generated by vascular and perivascular cells, such as in the case of endothelium-derived neurotrophin-3 (Delgado et al., 2014). Third, via diffusible signals that BVs transport but don't generate themselves. In small organisms, such as planarians, nutrients can be diffused directly from the environment, and in insects NSCs are directly bathed in the hemeolymph (Limmer et al., 2014; Spéder and Brand, 2014). In larger animals blood circulation is required for necessary factors to reach their target areas. One such example, crucial for NSCs, is insulin (Masjkur et al., 2012). Recently we have identified a possible fourth mechanism, in which the function of NSCs is controlled by platelets (a circulatory element), possibly via active mediation by endothelial cells (elements of the BV structure; Kazanis et al., 2015).

\section{What is the Nature of a NSC?}

It remains challenging to define what a NSC is and when it is reduced to neural progenitor status (exhibiting a more restricted potential). Here, we adopt an extended version of the unified hypothesis (Alvarez-Buylla et al., 2001), according to which the cardinal NSC properties are found equally in primitive/early NSCs with a neuroepithelial-like phenotype, in more developed cells with a radial glial phenotype and in some species (mostly in mammals), in mature cells with an astroglial phenotype (Figure 1). A surprising deviation was recently reported in the adult crayfish brain, in which the neurogenic stem cell pool does not contain bona fide NSCs but is constantly replenished from the hematopoietic system. Vascular extensions of the cerebral artery facilitate this process and this is an intriguing example of vessel-dependent support of neurogenesis (Chaves da Silva et al., 2013; Benton et al., 2014).

\section{THE ROLE OF THE VASCULATURE}

\section{Specification}

The in vitro (e.g., from iPSC differentiation or transdifferentiation experiments) and in vivo (e.g., from early embryonic developmental stages, or from evolutionary evidence based on zoological observations) data currently available indicate that the specification of pluripotent stem cells towards 
a neural identity does not depend on any form of interaction with some type of vasculature. The first neuron-like sensory cells and primitive nervous systems appeared in species that lacked BVs (Jékely et al., 2015) and the specification of neuroectoderm and of neuroepithelial cells in mammals marginally precedes the angiogenic specification of mesoderm in the forebrain (Vasudevan et al., 2008; Javaherian and Kriegstein, 2009). Nevertheless, after the closure of the neural tube, the primitive neuroepithelium remains in contact with a CSF-like fluid that is partly constituted by the early BV network of deeper layers (Lun et al., 2015).

\section{Proliferation/Diversification}

As soon as NSCs become specified the processes of selfrenewal and expansion are initiated. Low levels of proliferation, adequate for the generation of single neurons and glia and for the construction of primitive neuronal networks and of the early neural tube, can occur in the absence of vascularization (Rodriguez Celin et al., 2015). The emergence of larger and more complicated nervous systems required higher levels of proliferation in embryonic neural stem and progenitor cells, and this was partly achieved through their diversification. The evolution of the neocortex was facilitated by the appearance of radial glial-type NSCs (see "What is the Nature of a NSC?" Section) that exhibit high self-renewing potential and generate transit amplifying progenitors that significantly increase the cellgeneration capacity per initial NSC. Gyrenecephalia-mainly observed in primates-is also correlated with the addition of outer subventricular zone progenitors (Florio and Huttner, 2014). This evolutionary process of expansion of the embryonic NSC pool through diversification has not been cell-autonomous, with the embryonic microenvironment (the extracellular matrix, for example) playing a crucial role (Garcion et al., 2004; Loulier et al., 2009; Fietz et al., 2012; Pollen et al., 2015). However, only limited evidence exists to suggest a contribution of the vasculature. The chicken germinal cortical zones remain largely a-vascular (Rodriguez Celin et al., 2015) and in mice, even though BVs appear at the time of expansion of the neuroepithelial cell pool, only transit amplifying neural progenitors proliferate in close proximity to them (Vasudevan et al., 2008; Javaherian and Kriegstein, 2009). Nevertheless, in both examples the long basal processes of radial glia remain in constant contact with BVs positioned deeper in the tissue (Vasudevan et al., 2008; Rodriguez Celin et al., 2015) a feature shared by adult NSCs (Mirzadeh et al., 2008).

In the postnatal mammalian brain active NSCs survive in specialized NSC niches (Kazanis, 2013) and accumulating evidence points to the vasculature as an important element of these microenvironments (Goldman and Chen, 2011). The BV bed in the NSC niche of the subependymal zone (SEZlocated at the lateral walls of the lateral ventricles) is different from all neighboring areas: the density of BVs is higher and vessels are positioned differently in respect to the plane of the ventricle (Figures 2C,E; Kazanis et al., 2010; Culver et al., 2013). Furthermore, BVs are more leaky (Tavazoie et al., 2008) and blood flow is slower, suggesting the existence of hypoxic conditions (Culver et al., 2013). This finding is consistent with reports revealing enhanced efficiency in culturing neural progenitors under hypoxia (Stacpoole et al., 2013). On the other hand, we have shown that in evolution-for example, when comparing rodent brains of different sizes-the number of adult NSCs that populate the niche correlates strictly with the number of ependymal cells and not with the volume of the niche that would reflect the volume of the vasculature (Kazanis and ffrench-Constant, 2012). This strengthens the hypothesis that during evolution/development the role of the vasculature becomes crucial for NSCs after they have been established in the system. Adult NSCs remain in a stage of quiescence (Doetsch et al., 1999). We have shown that NSCs are preferentially positioned next to the ependyma (Kazanis et al., 2010; Kazanis and ffrench-Constant, 2012), which produces pro-neurogenic signals such as noggin (Lim et al., 2000). However, recent experimental work revealed that NSC quiescence is controlled via direct cell-to-cell contacts with endothelial cells (Ottone et al., 2014) and via the activity of diffusible endotheliumderived factors such as neurotrophin-3, angiopoietins 1 and 2 and placental growth factor 2 (PlGF-2; Masjkur et al., 2012; Delgado et al., 2014; Crouch et al., 2015; see also reviews of Goldman and Chen, 2011; Ottone and Parrinello, 2015). In contrast, the mitotically active transit amplifying progenitors are physically located in close proximity to BVs and specifically in domains void of astrocytic endfeet and pericytes (Mirzadeh et al., 2008; Shen et al., 2008; Tavazoie et al., 2008). However, our work also indicates that the proximity to BVs cannot be the only factor controlling adult neural progenitor activity because within the narrow architecture of the niche mitotic cells are often positioned only at the side of BVs facing the lateral ventricle (Kazanis et al., 2010) while numerous proliferating progenitors can be also found away from BVs (Figures 2A,B).

In homeostatic conditions the majority of cells generated in adult niches die via apoptosis (Morshead and van der Kooy, 1992; Morshead et al., 1998). An alternative pathway is senescence: the exit from the cell cycle without differentiation. Senescence has not been properly investigated in adult NSCs, with the exception of one report on oligodendrocyte progenitor cells entering senescence during ageing (Kujuro et al., 2010). We and others have observed that a small fraction of adult NSCs show signs of senescence when cultured in vitro (Figure 2; Ross et al., 2008). We have also reported that senescent cells can be detected in the ventral domain of the SEZ even in young adult rats (Kazanis et al., 2013) and that in the same area normal mitotic activity and response of NSCs to injury are significantly weaker when compared to dorsal domains (Kazanis et al., 2013). Furthermore, the occurrence of senescent cells spreads dorsally over time (Figure 2), a phenomenon that seems to correlate with the gradual age-related shrinkage of the SEZ (Shook et al., 2012). So far there is no evidence that the BV network shows significant structural or functional variation among different domains of the niche (for example, in the ventral areas) or that this might be crucial in the occurrence of senescence. However, the observation that mitotically active progenitors are located 


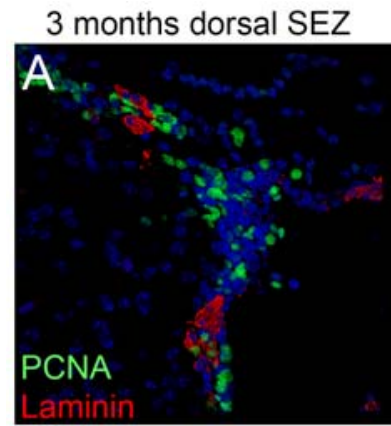

\section{3 months middle SEZ}

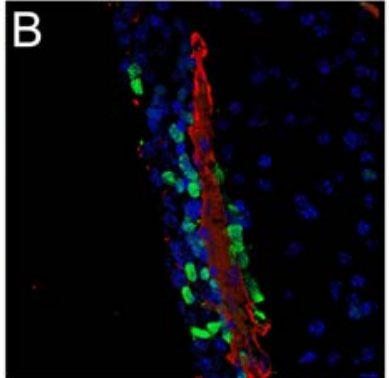

3 months middle SEZ

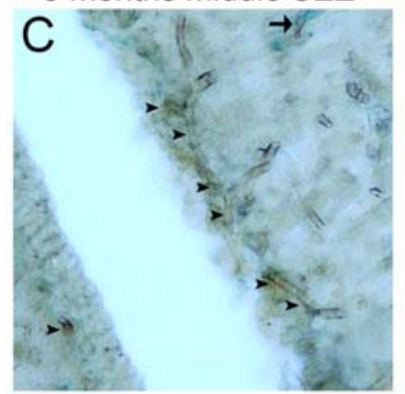

15 months middle SEZ

D

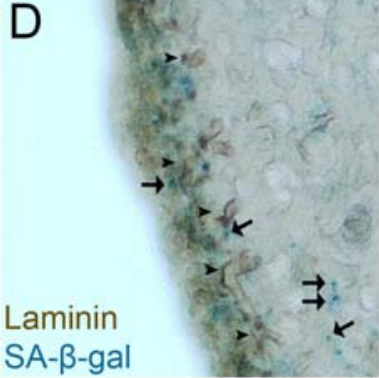

3 months ventral SEZ
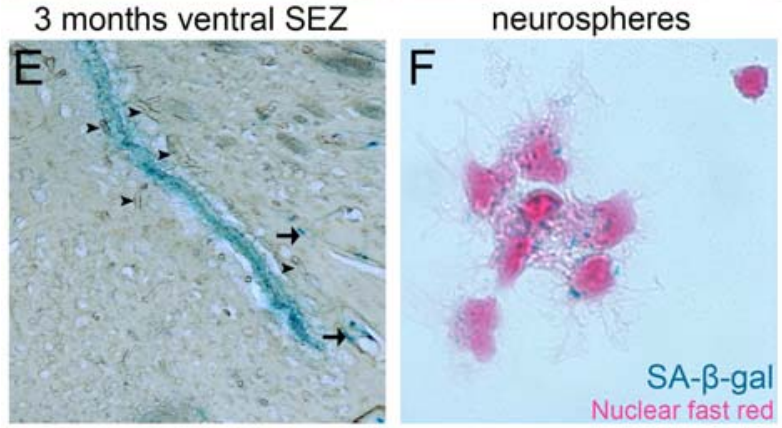

FIGURE 2 | Proliferation and senescence in the subependymal zone (SEZ). (A,B) High magnification photographs of domains of the SEZ (dorsal in A, middle in B) taken from young adult mouse brain tissue immunostained for PCNA (to mark proliferating cells) and laminin (to mark blood vessels, BVs). Note the existence of multiple proliferating cells around the long BV running in parallel to the lateral ventricle in (B), but also the existence of high proliferative activity in areas distant from BVs in (A). (C-E) High magnification photographs of domains of the SEZ (middle in $\mathbf{C , D}$ and ventral in $\mathbf{E}$ ) taken from young (in $\mathbf{C}, \mathbf{E}$ ) and aged (in $\mathbf{D}$ ) rat brain tissue immunostained for laminin and chemically stained for senescence-associated $\beta$ gal (in blue). Arrowheads indicate BVs and arrows senescent cells. Note the significantly lower density of BVs at the non-neurogenic side of the lateral ventricle (at the left of $\mathbf{C}$ ), the existence of senescent cells along BVs outside the SEZ and the existence of high numbers of senescent cells in the ventral domain of the young-adult rat SEZ (in E). (F) High magnification of adult mouse NSCs isolated from the SEZ and kept in culture. Note the existence of senescent cells (nuclei are counterstained with nuclear fast red). [Antibodies used: rabbit anti-laminin: 1/500 (Abcam), mouse anti-PCNA: 1/500 (Abcam). Alexa goat anti-rabbit 568 and goat anti-mouse 488 (Invitrogen). Biotinylated goat anti-rabbit and DAB staining kit (Vector laboratories). Senescence-associated $\beta$ gal staining kit (Millipore). Adult NSCs cultured in DMEM/F12 supplemented with B27 (Gibco), FGF2 $(20 \mathrm{ng} / \mathrm{ml})$ and EGF $(20 \mathrm{ng} / \mathrm{ml})$. All animal work was performed in accordance with the UK Animals (Scientific Procedures) Act 1986 and was approved by the University of Cambridge Animal Welfare and Ethical Review Body]. proximal to BVs can lead to the hypothesis that remoteness from BVs might be correlated with senescence, or even cell death of NSCs.

\section{Commitment and Differentiation}

It could be hypothesized that as the brain became larger and more complicated during evolution, the contribution of BVs in controlling the commitment and differentiation of NSC increased. Interestingly, similarly to diversification, there is no strong evidence on the existence of such dependance. The single example of a vessel-derived factor regulating cell fate decisions is pigment epithelium-derived factor (PEDF) that acts to instruct adult NSCs of the SEZ to switch mode of division from asymmetric differentiating to self-renewing (Ramírez-Castillejo et al., 2006). More specific to differentiation is the role of PlGF-2, diffused from endothelial cells and pericytes, that was recently shown to bias cell fate of adult NSCs and transit amplifying progenitors towards neurogenesis, at the expense of astrogliogenesis (Crouch et al., 2015). Enhanced neurogenesis was also observed in co-cultures of human NSCs and endothelial cells; albeit via unknown mechanisms (Chou et al., 2014). The available evidence suggests that cell fate choices are primarily controlled in a cell-autonomous manner, as has been shown from in vitro cultures of isolated embryonic and adult NSCs (Okano and Temple, 2009; Ortega et al., 2013). It should be noted that $\mathrm{BV}$-derived signals might not be essential for instructing cell-fate of neural stem and progenitor cells, but for the survival of certain types of newborn neurons (Kirschenbaum and Goldman, 1995; Leventhal et al., 1999), a "selection" role that can give the illusion of an effect on cell-fate instruction.

\section{Migration}

During embryonic development neural stem and progenitor cells migrate using radial glial processes, while adult SEZ-derived neuroblasts use chain-migration to exit the niche and reach their target area via an extracellular matrix-rich corridor, the rostral migratory stream. The first solid evidence that BVs also play a role in migration of neural progenitors came from animal models of cerebral ischemia, in which neuroblasts were shown to migrate towards the area of infarction along BVs (Yamashita et al., 2006; Thored et al., 2007; Kojima et al., 2010). Subsequently, vesselsupported migration was also found to be part of the homeostatic movement of neural progenitors, either in the granular cell layer in the hippocampus (Sun et al., 2015), or along the rostral migratory stream (Bovetti et al., 2007) and within the olfactory bulbs (Bovetti et al., 2007). Even more recently, BVs were shown to facilitate migration of oligodendroglial progenitors from the SEZ to the corpus callosum (Cayre et al., 2013) and the invasion of glioblastoma tumour cells into neighboring areas of the brain (Dubois et al., 2014). In the SEZ, SDF1/CXCL12 acts to attract neuroblasts expressing the CXCR4 receptor toward BVs (Kokovay et al., 2010), while endothelial-derived BDNF has been implicated to the attraction of neuroblasts to ischemic areas (Grade et al., 2013) and netrin-1 is necessary for the migration of oligodendroglial progenitors to the corpus callosum (Cayre et al., 2013). Overall, accumulating evidence indicates that migration 
is one phase in the life of NSCs that is highly dependent on the vasculature.

\section{COUPLING OF NEUROGENESIS AND ANGIOGENESIS; WHO NEEDS WHOM?}

A strong correlation between angiogenic and neurogenic events has been observed but the functional substrate remains elusive; hence, the term "coupling" has been adopted. Such coupling events have been described in the developing rodent nervous system, in which endothelial cells share expression of transcription factors with surrounding NSCs according to the anatomical location (Vasudevan et al., 2008) and in the plastic areas of the adult song-bird. Moreover, in the post-stroke recovery in the adult rodent brain, induction of angiogenesis and of NSC-driven cytogenesis seem to be co-ordinated (Thored et al., 2007; Plane et al., 2010; Zhang et al., 2014), while pulses of synchronous NSC proliferation in the SEZ induce increased blood flow (Lacar et al., 2012a). Although some architectural and structural specializations of the adult NSC niche vasculature have been described, leading to the use of the term "neurovascular" niche, the absence of a functional specialization in BVs outside the niche has not yet been proven. Recent experimental work demonstrated that isolated endothelial cells from non-neurogenic areas of the adult brain exhibit equal, if not superior, potential in promoting NSC proliferation and differentiation when compared to endothelial cells from neurogenic areas (Crouch et al., 2015). In addition, mitotically active oligodendrocyte progenitors in the brain parenchyma have been reported to cross-talk with endothelial cells within "oligovascular niches" (Arai and Lo, 2009; Pham et al., 2012). Notably, in experimental animal models of stroke or multiple sclerosis, transplanted NSCs form "atypical neurovascular niches" using BVs outside the established stem cell areas (Pluchino et al., 2010). Finally, accumulating evidence suggests that dormant NSCs exist in the non-neurogenic brain parenchyma of rodents (Sirko et al., 2013), possibly next to BVs (Bardehle et al., 2013), and that in the human brain such progenitors might not be dormant at all (Ernst et al., 2014). On the other hand, we have observed that, in response to a demyelinating lesion in the corpus callosum, platelets accumulate specifically in the vasculature of the SEZ, suggesting an underlying specialization of BVs (Kazanis et al., 2015). Furthermore, by staining for senescence-associated markers we have also observed that although a high number of endothelial cells

\section{REFERENCES}

Alvarez-Buylla, A., García-Verdugo, J. M., and Tramontin, A. D. (2001). A unified hypothesis on the lineage of neural stem cells. Nat. Rev. Neurosci. 2, 287-293. doi: $10.1038 / 35067582$

Androutsellis-Theotokis, A., Rueger, M. A., Park, D. M., Boyd, J. D., Padmanabhan, R., Campanati, L., et al. (2010). Angiogenic factors stimulate growth of adult neural stem cells. PLoS One 5:e9414. doi: 10.1371/journal.pone. 0009414 in BVs spread throughout the adult rat brain are senescent, the niche vasculature remains senescence-free (Figure 2), a possible indication of higher vascular plasticity potential in the specific area.

Another significant aspect of the cross-talk between BVs and NSCs is the transport of factors that might be important to NSCs but are not produced by vascular and perivascular cells. Two examples have already been mentioned: oxygen (Lacar et al., 2012a; Culver et al., 2013) and insulin (Masjkur et al., 2012). Recent experimental work has also revealed that blood-derived factors, such as GDF11, can act to rejuvenate aged neural stem and progenitor cells (Ruckh et al., 2012; Katsimpardi et al., 2014). In other words, by feeding the aged brain with young blood, scientists were able to reverse some of the effects of ageing on NSCs. However, it still remains unknown if the effect was direct to NSCs or if it was dependent on rejuvenating the vasculature or macrophages. A final and intriguing aspect is the possible instructive role of NSCs on the vasculature. The dominant hypothesis is that the vasculature directs NSCs, exemplified by the observation that grafted NSCs are ectopically homed perivascularly (Pluchino et al., 2010). However, SEZ NSCs can influence the function of BVs, for example, the blood flow (Lacar et al., 2012b), and oligodendrocyte progenitors can control angiogenesis through hypoxia-inducible factors (Yuen et al., 2014). These are in concert with evidence that embryonic cortical NSCs are important for the establishment of the developing vasculature (Gerhardt et al., 2004; Ma et al., 2013) and that in many cases vascularization tightly follows the maturation of the nervous system (Rodriguez Celin et al., 2015). Recently published work with human NSCs also showed that they provide the necessary juxtacrine and paracrine signals to drive human endothelial cells to form "vasculature-like structures" (Chou et al., 2014) and promote angiogenesis in the rodent brain (Hicks et al., 2013). Therefore, the bidirectional cross-talk between NSCs and BVs is a line of research that needs to be developed further.

\section{AUTHOR CONTRIBUTIONS}

CK contributed original data wrote and approved the manuscript. IK contributed original data, developed the concept, wrote and approved the manuscript.

\section{FUNDING}

IK was supported by Action Medical Research, UK (GN2291).
Arai, K., and Lo, E. H. (2009). An oligovascular niche: cerebral endothelial cells promote the survival and proliferation of oligodendrocyte precursor cells. J. Neurosci. 29, 4351-4355. doi: 10.1523/JNEUROSCI.0035-09.2009

Bardehle, S., Krüger, M., Buggenthin, F., Schwausch, J., Ninkovic, J., Clevers, H., et al. (2013). Live imaging of astrocyte responses to acute injury reveals selective juxtavascular proliferation. Nat. Neurosci. 16, 580-586. doi: 10.1038/nn.3371

Benton, J. L., Kery, R., Li, J., Noonin, C., Söderhäll, I., and Beltz, B. S. (2014). Cells from the immune system generate adult-born neurons in crayfish. Dev. Cell 30, 322-333. doi: 10.1016/j.devcel.2014.06.016 
Bovetti, S., Hsieh, Y.-C., Bovolin, P., Perroteau, I., Kazunori, T., and Puche, A. C. (2007). Blood vessels form a scaffold for neuroblast migration in the adult olfactory bulb. J. Neurosci. 27, 5976-5980. doi: 10.10.1523/JNEUROSCI.067807.2007

Cayre, M., Courtès, S., Martineau, F., Giordano, M., Arnaud, K., Zamaron, A., et al. (2013). Netrin 1 contributes to vascular remodeling in the subventricular zone and promotes progenitor emigration after demyelination. Development 140, 3107-3117. doi: 10.1242/dev.092999

Chaves da Silva, P. G., Benton, J. L., Sandeman, D. C., and Beltz, B. S. (2013). Adult neurogenesis in the crayfish brain: the hematopoietic anterior proliferation center has direct access to the brain and stem cell niche. Stem Cells Dev. 22, 1027-1041. doi: 10.1089/scd.2012.0583

Chou, C.-H., Sinden, J. D., Couraud, P.-O., and Modo, M. (2014). In vitro modeling of the neurovascular environment by coculturing adult human brain endothelial cells with human neural stem cells. PLoS One 9:e106346. doi: 10. 1371/journal.pone.0106346

Crouch, E. E., Liu, C., Silva-Vargas, V., and Doetsch, F. (2015). Regional and stage-specific effects of prospectively purified vascular cells on the adult V-SVZ neural stem cell lineage. J. Neurosci. 35, 4528-4539. doi: 10.1523/JNEUROSCI. 1188-14.2015

Culver, J. C., Vadakkan, T. J., and Dickinson, M. E. (2013). A specialized microvascular domain in the mouse neural stem cell niche. PLoS One 8:e53546. doi: 10.1371/journal.pone.0053546

Delgado, A. C., Ferrón, S. R., Vicente, D., Porlan, E., Perez-Villalba, A., Trujillo, C. M., et al. (2014). Endothelial NT-3 delivered by vasculature and CSF promotes quiescence of subependymal neural stem cells through nitric oxide induction. Neuron 83, 572-585. doi: 10.1016/j.neuron.2014.06

Doetsch, F., Caillé, I., Lim, D. A., García-Verdugo, J. M., and Alvarez-Buylla, A. (1999). Subventricular zone astrocytes are neural stem cells in the adult mammalian brain. Cell 97, 703-716. doi: 10.1016/s0092-8674(00)80783-7

Dubois, L. G., Campanati, L., Righy, C., D’Andrea-Meira, I., Spohr, T. C. L., PortoCarreiro, I., et al. (2014). Gliomas and the vascular fragility of the blood brain barrier. Front. Cell. Neurosci. 8:418. doi: 10.3389/fncel.2014.00418

Ernst, A., Alkass, K., Bernard, S., Salehpour, M., Perl, S., Tisdale, J., et al. (2014). Neurogenesis in the striatum of the adult human brain. Cell 156, 1072-1083. doi: 10.1016/j.cell.2014.01.044

Fietz, S. A., Lachmann, R., Brandl, H., Kircher, M., Samusik, N., Schröder, R., et al. (2012). Transcriptomes of germinal zones of human and mouse fetal neocortex suggest a role of extracellular matrix in progenitor self-renewal. Proc. Natl. Acad. Sci. U S A 109, 11836-11841. doi: 10.1073/pnas.1209647109

Florio, M., and Huttner, W. B. (2014). Neural progenitors, neurogenesis and the evolution of the neocortex. Development 141, 2182-2194. doi: 10.1242/dev. 090571

Garcion, E., Halilagic, A., Faissner, A., and ffrench-Constant, C. (2004). Generation of an environmental niche for neural stem cell development by the extracellular matrix molecule tenascin C. Development 131, 3423-3432. doi: 10. 1242/dev.01202

Gerhardt, H., Ruhrberg, C., Abramsson, A., Fujisawa, H., Shima, D., and Betsholtz, C. (2004). Neuropilin-1 is required for endothelial tip cell guidance in the developing central nervous system. Dev. Dyn. 231, 503-509. doi: 10. 1002/dvdy.20148

Goldman, S. A., and Chen, Z. (2011). Perivascular instruction of cell genesis and fate in the adult brain. Nat. Neurosci. 14, 1382-1389. doi: 10.1038/nn.2963

Grade, S., Weng, Y. C., Snapyan, M., Kriz, J., Malva, J. O., and Saghatelyan, A. (2013). Brain-derived neurotrophic factor promotes vasculature-associated migration of neuronal precursors toward the ischemic striatum. PLoS One 8:e55039. doi: 10.1371/journal.pone.0055039

Hicks, C., Stevanato, L., Stroemer, R. P., Tang, E., Richardson, S., and Sinden, J. D. (2013). In vivo and in vitro characterization of the angiogenic effect of CTX0E03 human neural stem cells. Cell Transplant. 22, 1541-1552. doi: 10. 3727/096368912x657936

Javaherian, A., and Kriegstein, A. (2009). A stem cell niche for intermediate progenitor cells of the embryonic cortex. Cereb. Cortex 19, i70-i77. doi: 10. 1093/cercor/bhp029

Jékely, G., Paps, J., and Nielsen, C. (2015). The phylogenetic position of ctenophores and the origin(s) of nervous systems. Evodevo 6:1. doi: 10. 1186/2041-9139-6-1

Katsimpardi, L., Litterman, N. K., Schein, P. A., Miller, C. M., Loffredo, F. S., Wojtkiewicz, G. R., et al. (2014). Vascular and neurogenic rejuvenation of the aging mouse brain by young systemic factors. Science 344, 630-634. doi: 10 . $1126 /$ science. 1251141

Kazanis, I. (2013). Neurogenesis in the adult mammalian brain: how much do we need, how much do we have? Curr. Top. Behav. Neurosci. 15, 3-29. doi: 10. 1007/7854_2012_227

Kazanis, I., Feichtner, M., Lange, S., Rotheneichner, P., Hainzl, S., Öller, M., et al. (2015). Lesion-induced accumulation of platelets promotes survival of adult neural stem/progenitor cells. Exp. Neurol. 269, 75-89. doi: 10.1016/j.expneurol. 2015.03.018

Kazanis, I., and ffrench-Constant, C. (2012). The number of stem cells in the subependymal zone of the adult rodent brain is correlated with the number of ependymal cells and not with the volume of the niche. Stem Cells Dev. 21, 1090-1096. doi: 10.1089/scd.2011.0130

Kazanis, I., Gorenkova, N., Zhao, J. W., Franklin, R. J. M., Modo, M., and ffrenchConstant, C. (2013). The late response of rat subependymal zone stem and progenitor cells to stroke is restricted to directly affected areas of their niche. Exp. Neurol. 248, 387-397. doi: 10.1016/j.expneurol.2013.06.025

Kazanis, I., Lathia, J. D., Vadakkan, T. J., Raborn, E., Wan, R., Mughal, M. R., et al. (2010). Quiescence and activation of stem and precursor cell populations in the subependymal zone of the mammalian brain are associated with distinct cellular and extracellular matrix signals. J. Neurosci. 30, 9771-9781. doi: 10. 1523/JNEUROSCI.0700-10.2010

Kirschenbaum, B., and Goldman, S. A. (1995). Brain-derived neurotrophic factor promotes the survival of neurons arising from the adult rat forebrain subependymal zone. Proc. Natl. Acad. Sci. US A 92, 210-214. doi: 10.1073/pnas. 92.1.210

Kojima, T., Hirota, Y., Ema, M., Takahashi, S., Miyoshi, I., Okano, H., et al. (2010). Subventricular zone-derived neural progenitor cells migrate along a blood vessel scaffold toward the post-stroke striatum. Stem Cells 28, 545-554. doi: 10.1002/stem.306

Kokovay, E., Goderie, S., Wang, Y., Lotz, S., Lin, G., Sun, Y., et al. (2010). Adult SVZ lineage cells home to and leave the vascular niche via differential responses to SDF1/CXCR4 signaling. Cell Stem Cell 7, 163-173. doi: 10.1016/j.stem.2010. 05.019

Kujuro, Y., Suzuki, N., and Kondo, T. (2010). Esophageal cancer-related gene 4 is a secreted inducer of cell senescence expressed by aged CNS precursor cells. Proc. Natl. Acad. Sci. U S A 107, 8259-8264. doi: 10.1073/pnas.09114 46107

Lacar, B., Herman, P., Hartman, N. W., Hyder, F., and Bordey, A. (2012a). S phase entry of neural progenitor cells correlates with increased blood flow in the young subventricular zone. PLoS One 7:e31960. doi: 10.1371/journal.pone. 0031960

Lacar, B., Herman, P., Platel, J.-C., Kubera, C., Hyder, F., and Bordey, A (2012b). Neural progenitor cells regulate capillary blood flow in the postnatal subventricular zone. J. Neurosci. 32, 16435-16448. doi: 10.1523/JNEUROSCI. 1457-12.2012

Leventhal, C., Rafii, S., Rafii, D., Shahar, A., and Goldman, S. A. (1999) Endothelial trophic support of neuronal production and recruitment from the adult mammalian subependyma. Mol. Cell. Neurosci. 13, 450-464. doi: 10. 1006/mcne.1999.0762

Lim, D. A., Tramontin, A. D., Trevejo, J. M., Herrera, D. G., García-Verdugo, J. M., and Alvarez-Buylla, A. (2000). Noggin antagonizes BMP signaling to create a niche for adult neurogenesis. Neuron 28, 713-726. doi: 10.1016/s08966273(00)00148-3

Limmer, S., Weiler, A., Volkenhoff, A., Babatz, F., and Klämbt, C. (2014). The Drosophila blood-brain barrier: development and function of a glial endothelium. Front. Neurosci. 8:365. doi: 10.3389/fnins.2014.00365

Louissaint, A., Rao, S., Leventhal, C., and Goldman, S. A. (2002). Coordinated interaction of neurogenesis and angiogenesis in the adult songbird brain. Neuron 34, 945-960. doi: 10.1016/S0896-6273(02)00722-5

Loulier, K., Lathia, J. D., Marthiens, V., Relucio, J., Mughal, M. R., Tang, S.-C., et al. (2009). $\beta 1$ integrin maintains integrity of the embryonic neocortical stem cell niche. PLoS Biol. 7:e1000176. doi: 10.1371/journal.pbio.1000176

Lun, M. P., Monuki, E. S., and Lehtinen, M. K. (2015). Development and functions of the choroid plexus-cerebrospinal fluid system. Nat. Rev. Neurosci. 16 445-457. doi: 10.1038/nrn3921

Ma, S., Kwon, H. J., Johng, H., Zang, K., and Huang, Z. (2013). Radial glial neural progenitors regulate nascent brain vascular network stabilization via inhibition of Wnt signaling. PLoS Biol. 11:e1001469. doi: 10.1371/journal.pbio.1001469 
Masjkur, J., Rueger, M. A., Bornstein, S. R., McKay, R., and AndroutsellisTheotokis, A. (2012). Neurovascular signals suggest a propagation mechanism for endogenous stem cell activation along blood vessels. CNS Neurol. Disord. Drug Targets 11, 805-817. doi: 10.2174/1871527311201070805

Mirzadeh, Z., Merkle, F. T., Soriano-Navarro, M., Garcia-Verdugo, J. M., and Alvarez-Buylla, A. (2008). Neural stem cells confer unique pinwheel architecture to the ventricular surface in neurogenic regions of the adult brain. Cell Stem Cell 3, 265-278. doi: 10.1016/j.stem.2008.07.004

Morshead, C. M., Craig, C. G., and van der Kooy, D. (1998). In vivo clonal analyses reveal the properties of endogenous neural stem cell proliferation in the adult mammalian forebrain. Development 125, 2251-2261.

Morshead, C. M., and van der Kooy, D. (1992). Postmitotic death is the fate of constitutively proliferating cells in the subependymal layer of the adult mouse brain. J. Neurosci. 12, 249-256.

Okano, H., and Temple, S. (2009). Cell types to order: temporal specification of CNS stem cells. Curr. Opin. Neurobiol. 19, 112-119. doi: 10.1016/j.conb.2009. 04.003

Ortega, F., Gascón, S., Masserdotti, G., Deshpande, A., Simon, C., Fischer, J., et al. (2013). Oligodendrogliogenic and neurogenic adult subependymal zone neural stem cells constitute distinct lineages and exhibit differential responsiveness to Wnt signalling. Nat. Cell Biol. 15, 602-613. doi: 10.1038/ncb2736

Ottone, C., Krusche, B., Whitby, A., Clements, M., Quadrato, G., Pitulescu, M. E., et al. (2014). Direct cell-cell contact with the vascular niche maintains quiescent neural stem cells. Nat. Cell Biol. 16, 1045-1056. doi: 10.1038/ncb3045

Ottone, C., and Parrinello, S. (2015). Multifaceted control of adult SVZ neurogenesis by the vascular niche. Cell Cycle 14, 2222-2225. doi: 10 . 1080/15384101.2015.1049785

Pham, L.-D. D., Hayakawa, K., Seo, J. H., Nguyen, M.-N., Som, A. T., Lee, B. J., et al. (2012). Crosstalk between oligodendrocytes and cerebral endothelium contributes to vascular remodeling after white matter injury. Glia 60, 875-881. doi: $10.1002 /$ glia. 22320

Plane, J. M., Andjelkovic, A. V., Keep, R. F., and Parent, J. M. (2010). Intact and injured endothelial cells differentially modulate postnatal murine forebrain neural stem cells. Neurobiol. Dis. 37, 218-227. doi: 10.1016/j.nbd.2009.10.008

Pluchino, S., Cusimano, M., Bacigaluppi, M., and Martino, G. (2010). Remodelling the injured CNS through the establishment of atypical ectopic perivascular neural stem cell niches. Arch. Ital. Biol. 148, 173-183.

Pollen, A. A., Nowakowski, T. J., Chen, J., Retallack, H., Sandoval-Espinosa, C., Nicholas, C. R., et al. (2015). Molecular identity of human outer radial glia during cortical development. Cell 163, 55-67. doi: 10.1016/j.cell.2015. 09.004

Ramírez-Castillejo, C., Sánchez-Sánchez, F., Andreu-Agulló, C., Ferrón, S. R., Aroca-Aguilar, J. D., Sánchez, P., et al. (2006). Pigment epithelium-derived factor is a niche signal for neural stem cell renewal. Nat. Neurosci. 9, 331-339. doi: $10.1038 / \mathrm{nn} 1657$

Rodriguez Celin, A., Rapacioli, M., Gonzalez, M. A., Ballarin, V. L., de Plazas, S. F., López-Costa, J. J., et al. (2015). Temporal-spatial correlation between angiogenesis and corticogenesis in the developing chick optic tectum. PLoS One 10:e0116343. doi: 10.1371/journal.pone.0116343

Ross, H. H., Levkoff, L. H., Marshall, G. P., Caldeira, M., Steindler, D. A., Reynolds, B. A., et al. (2008). Bromodeoxyuridine induces senescence in neural stem and progenitor cells. Stem Cells 26, 3218-3227. doi: 10.1634/stemcells. 2008-0299

Ruckh, J. M., Zhao, J.-W., Shadrach, J. L., van Wijngaarden, P., Rao, T. N., Wagers, A. J., et al. (2012). Rejuvenation of regeneration in the aging central nervous system. Cell Stem Cell 10, 96-103. doi: 10.1016/j.stem.2011. 11.019

Satterlie, R. A. (2015). The search for ancestral nervous systems: an integrative and comparative approach. J. Exp. Biol. 218, 612-617. doi: 10.1242/jeb. 110387
Shen, Q., Goderie, S. K., Jin, L., Karanth, N., Sun, Y., Abramova, N., et al. (2004). Endothelial cells stimulate self-renewal and expand neurogenesis of neural stem cells. Science 304, 1338-1340. doi: 10.1126/science.1095505

Shen, Q., Wang, Y., Kokovay, E., Lin, G., Chuang, S.-M., Goderie, S. K., et al. (2008). Adult SVZ stem cells lie in a vascular niche: a quantitative analysis of niche cell-cell interactions. Cell Stem Cell 3, 289-300. doi: 10.1016/j.stem.2008. 07.026

Shook, B. A., Manz, D. H., Peters, J. J., Kang, S., and Conover, J. C. (2012). Spatiotemporal changes to the subventricular zone stem cell pool through aging. J. Neurosci. 32, 6947-6956. doi: 10.1523/JNEUROSCI.5987-11.2012

Sirko, S., Behrendt, G., Johansson, P. A., Tripathi, P., Costa, M., Bek, S., et al. (2013). Reactive glia in the injured brain acquire stem cell properties in response to sonic hedgehog. [corrected]. Cell Stem Cell 12, 426-439. doi: 10. 1016/j.stem.2013.01.019

Spéder, P., and Brand, A. H. (2014). Gap junction proteins in the blood-brain barrier control nutrient-dependent reactivation of Drosophila neural stem cells. Dev. Cell 30, 309-321. doi: 10.1016/j.devcel.2014.05.021

Stacpoole, S. R. L., Webber, D. J., Bilican, B., Compston, A., Chandran, S., and Franklin, R. J. M. (2013). Neural precursor cells cultured at physiologically relevant oxygen tensions have a survival advantage following transplantation. Stem Cells Transl. Med. 2, 464-472. doi: 10.5966/sctm.2012-0144

Sun, G. J., Zhou, Y., Stadel, R. P., Moss, J., Yong, J. H. A., Ito, S., et al. (2015). Tangential migration of neuronal precursors of glutamatergic neurons in the adult mammalian brain. Proc. Natl. Acad. Sci. U S A 112, 9484-9489. doi: 10. 1073/pnas. 1508545112

Tavazoie, M., Van der Veken, L., Silva-Vargas, V., Louissaint, M., Colonna, L., Zaidi, B., et al. (2008). A specialized vascular niche for adult neural stem cells. Cell Stem Cell 3, 279-288. doi: 10.1016/j.stem.2008.07.025

Thored, P., Wood, J., Arvidsson, A., Cammenga, J., Kokaia, Z., and Lindvall, O. (2007). Long-term neuroblast migration along blood vessels in an area with transient angiogenesis and increased vascularization after stroke. Stroke 38, 3032-3039. doi: 10.10.1161/STROKEAHA.107.488445

Vasudevan, A., Long, J. E., Crandall, J. E., Rubenstein, J. L. R., and Bhide, P. G. (2008). Compartment-specific transcription factors orchestrate angiogenesis gradients in the embryonic brain. Nat. Neurosci. 11, 429-439. doi: 10 1038/nn2074

Yamashita, T., Ninomiya, M., Hernández Acosta, P., García-Verdugo, J. M., Sunabori, T., Sakaguchi, M., et al. (2006). Subventricular zone-derived neuroblasts migrate and differentiate into mature neurons in the post-stroke adult striatum. J. Neurosci. 26, 6627-6636. doi: 10.1523/JNEUROSCI.014906.2006

Yuen, T. J., Silbereis, J. C., Griveau, A., Chang, S. M., Daneman, R., Fancy, S. P. J., et al. (2014). Oligodendrocyte-encoded HIF function couples postnatal myelination and white matter angiogenesis. Cell 158, 383-396. doi: 10.1016/j. cell.2014.04.052

Zhang, R. L., Chopp, M., Roberts, C., Liu, X., Wei, M., Nejad-Davarani, S. P., et al. (2014). Stroke increases neural stem cells and angiogenesis in the neurogenic niche of the adult mouse. PLoS One 9:e113972. doi: 10.1371/journal.pone. 0113972

Conflict of Interest Statement: The authors declare that the research was conducted in the absence of any commercial or financial relationships that could be construed as a potential conflict of interest.

Copyright (๑) 2016 Koutsakis and Kazanis. This is an open-access article distributed under the terms of the Creative Commons Attribution License (CC BY). The use, distribution and reproduction in other forums is permitted, provided the original author(s) or licensor are credited and that the original publication in this journal is cited, in accordance with accepted academic practice. No use, distribution or reproduction is permitted which does not comply with these terms. 